\title{
Evaluation of adherence to gluten-free diets in Moroccan celiac patients and factors of adherence failure
}

\author{
Morad Guennouni ${ }^{1, *}$, Aicha Bourrhouate $^{2}$, Noureddine El Khoudri ${ }^{1}$, Brahim Admou ${ }^{3}$, Rabiy El Qadiry ${ }^{2}$, Abdelmalek \\ Hakmaoui $^{2}$, and Abderraouaf Hilali ${ }^{1}$. \\ ${ }^{1}$ Hassan first University, Laboratory of Health Sciences and Technologies, Higher Institute of Health Sciences of Settat, Morocco \\ ${ }^{2}$ Dietary unit, University Hospital Centre Mohamed VI of Marrakesh, Faculty of medicine and pharmacy of Marrakech, Marrakech, \\ Morocco \\ ${ }^{3}$ Immunology laboratory, University Hospital Centre Mohamed VI of Marrakesh, Faculty of medicine and pharmacy of Marrakech
}

\begin{abstract}
The prevalence of celiac disease (CD) is increasing in the world. In Morocco, its incidence is also increasing considerably. The gluten-free diet (GFD) remains the only effective treatment so far. Its effectiveness depends essentially on good adherence to this diet. However, several factors hinder adherence by contributing to diet failure. Within this framework, this study aims to evaluate adherence to this diet in celiac children and adolescents continuing in a tertiary health center. The article also looks to identify the different factors influencing adherence to GFD in Morocco. The results show from serological and/or biopsy tests on 238 celiac patients that half had good adherence and $13 \%$ had poor adherence. The questionnaire aimed at 127 parents or proxies of celiac children and adolescents shows that several factors are responsible for the failure to adhere to the diet such as the role of the mass media, cultural and psychological factors. The exorbitant price, nutritional quality, and low availability of gluten-free products play a major role in GFD failure. Low socio-economic factors have a negative influence on the adherence to the GFD.
\end{abstract}

\section{INTRODUCTION}

The ingestion of gluten found in wheat (gliadin), barley (ordein), and rye (secalin) causes immune reactions in some susceptible people[1]. This is celiac disease (CD), which destroys intestinal villi by causing poor absorption of nutrients [2]. It affects about 0.7 to $1.4 \%$ of the world's population [3]. It affects their quality of life [4]. The gluten-free diet (GFD) remains the only treatment to follow [5]. The patient is obliged to consume only naturally gluten-free foods and/or foods developed by industrialists and labelled "gluten-free". However, adapting to this change in eating habits is a great challenge for these patients. It is a question of having a good adherence to this diet [6]. According to Sevinc[7], Serological tests (anti-transglutaminase antibodies, antideamidated gliadin peptid antibodies, and antiEndomysium antibodies) and/or duodenal biopsy can be used to confirm the disease and also to confirm level of adherence to GFD.

Good adherence to this diet corrects damage to the intestines and thus corrects the absorption of macros and micronutrients [8]. However, there are several factors that hinder good adhesion. These are the factors of failure to adhere to this regime. According to a review and metaanalysis conducted by MacCulloch et al. [9], cost, availability, labelling of gluten-free products (GFPs), are the factors of failure related to products used by celiac patients. In 2019, according to a joint review and metaanalysis by Xhakollari et al. [10], the review classifies the factors affecting GFD in eight groups: "Factors specific to the GFD"; "Socio-demographic factors"; "GF products' factors"; "Psychological Factors"; "Symptoms related to Celiac"; "Celiac Disease's factors"; "Quality of Life";
"Other Factors". However, no studies included in this review have been carried out in Africa. The overwhelming majority of the studies were carried out in Europe, North America, Australia, and South America by $47 \%, 29.7$ and $15 \%$ respectively. Asia was represented only by $2 \%[10]$. Highlighting the factors is essential for suggesting preventive and corrective actions to overcome factors and improve the level of adherence to this diet which is the only treatment for CD as well as any glutenrelated disease such as wheat allergy, gluten ataxia, dermatitis herpetiformis, sensitivity to non-coeliac gluten [11].

In Morocco, the prevalence of $\mathrm{CD}$ is unknown. However, the number of new cases is increasing considerably [12]. Hence, the need to have a good adherence to this GFD with the availability of all the factors of success to this adherence. It is within this framework that the objective of the present research is set. On the one hand, it is a question of highlighting the level of adherence to the GFD. On the other hand, the factors that contribute to the failure to adhere to the GFD should be determined.

\section{Materials and methods}

This study is divided into two parts. The first aims to assess adherence to the GFD. The second aims to determine the factors that contribute to the failure to adhere to the GFD.

To evaluate adherence to the GFD, serological tests (antitransglutaminase antibodies, anti-deamidated gliadin peptid antibodies, and anti-Endomysium antibodies) and/or duodenal biopsy were used to confirm level of

\footnotetext{
* Corresponding author: $\underline{\text { morad.guennouni@gmail.com // m.guennouni@uhp.ac.ma }}$
} 
adherence to GFD during each consultation. The study was carried out on 238 celiac children and adolescents. These patients were continued in a tertiary health center (CHU Mohamed VI of Marrakech) by pediatricians and dieticians between 2017 and 2020. Normal results in each appointment show good adherence to the GFD. Nonnormal results in each appointment show poor adherence to the GFD. Alternating results in the appointments show average adherence.

The evaluation of the GFD failure factors was carried out by means of a questionnaire. The survey questionnaire was divided into two parts:

- First part: Information on the socio-demographic criteria of the respondents: age, rural/urban, level of education, socio-professional category. Examples of questions in this section are as follows: What is your age group, what is your socio-professional category, what is your financial situation, etc.?

- Second part: it concerns the citation of factors for failure to adhere to the GFD. Parents or proxies of celiac children and adolescents cite, according to their opinions, the factors that prevent their children from having a very good adherence to the GFD. The questionnaire in Arabic language is self-self-administered or complete by interview face to face in illiterate parents cases. It involves choosing between product-related factors (Availability, cost, labeled, or nutritional quality of gluten-free products), access to counselling by pediatricians, knowledge about GFD, access to counselling by dieticians, awareness raising through the mass media and social networks, cooking at home, meals in food services, cultural factors, and social factors.

Data entry and analysis was performed using SPSS 25 software. The tests used are Multiple Correspondence Analysis (ACM); to study the relationship between ordinal qualitative variables, test $\chi^{2}$ Multiple Correspondence Analysis (ACM); to study the relationship between nominal or ordinal qualitative variables.

\section{Results and discussion}

\section{Adherence to gluten-free diet}

The study was carried out on 238 celiac children and adolescents between the ages of 2 and 15 . The female sex is the most represented in this research with 154 girls (64.7\%). However, the difference between the two sexes was non-significant $(\mathrm{p}=0.074)$.

The results of serological tests and intestinal biopsy showed that $52.94 \%$ of these patients represent good adherence to GFD. However, $13.87 \%$ of the patients showed poor adherence to the GFD. While $33.19 \%$ show an alternation between poor and good adherence. In the study conducted in Algeria in 2014, the prevalence of poor adherence was higher than in the present study $(48 \%$ vs. $13 \%)$ [13]. However, the prevalence of good adherence after GFD in India was very high (92\%)[14].

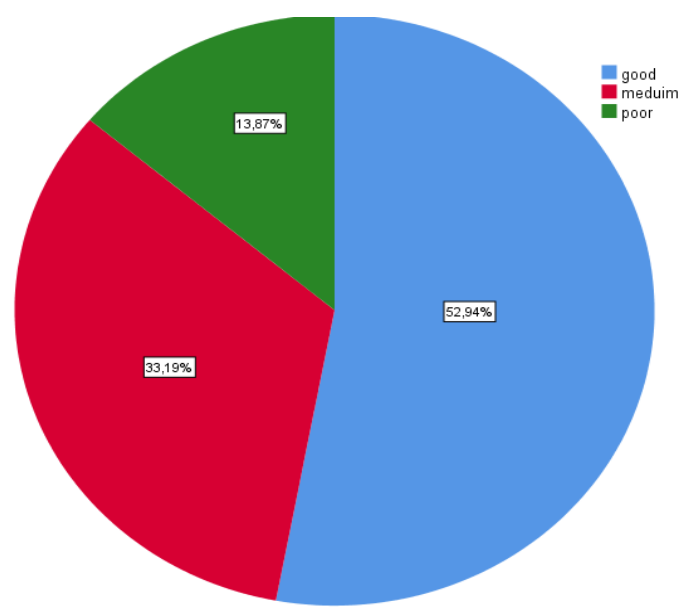

Fig. 1. prevalence of adherence to the gluten-free diet

Table 1 presents the impact of the origin of residence of celiac children and adolescents on adherence to the GFD. The Chi-square test shows that celiac children and adolescents residing in rural areas adhered better to the GFD than those in urban areas. The latter had a worse adherence than those in urban areas. The impact was with a highly significant difference $(\mathrm{p}<0.001)$ (Figure 1).

Table 1. Adherence to gluten-free diet according to living environment

\begin{tabular}{|c|c|c|c|c|c|}
\hline & & adher & $\begin{array}{l}\text { e to GFD } \\
\text { (n) }\end{array}$ & ffectif & \\
\hline & & good & meduim & poor & Iotal \\
\hline 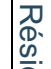 & Rural & 36 & 55 & 25 & 116 \\
\hline$\frac{\mathscr{R}}{2}$ & Urban & 90 & 24 & 8 & 122 \\
\hline & Total & 126 & 79 & 33 & 238 \\
\hline
\end{tabular}

$\mathrm{n}$ : effective $; \mathrm{p}<0.001$

Multiple Correspondent Analysis (MCA) has made it possible to show the correlation that exists between adherence and certain socio-economic and demographic factors whose variables are greater than 3. The MCA factor map shows that good adherence is correlated with children under 5 years of age. It is also correlated with people with average economic status. Failure to adhere is 
correlated mainly with illiterate parents with low economic status. It is also correlated with teenagers above the age of 12. Average adherence is rather correlated with children in the age group between 5 and 12 years old (Figure 2).

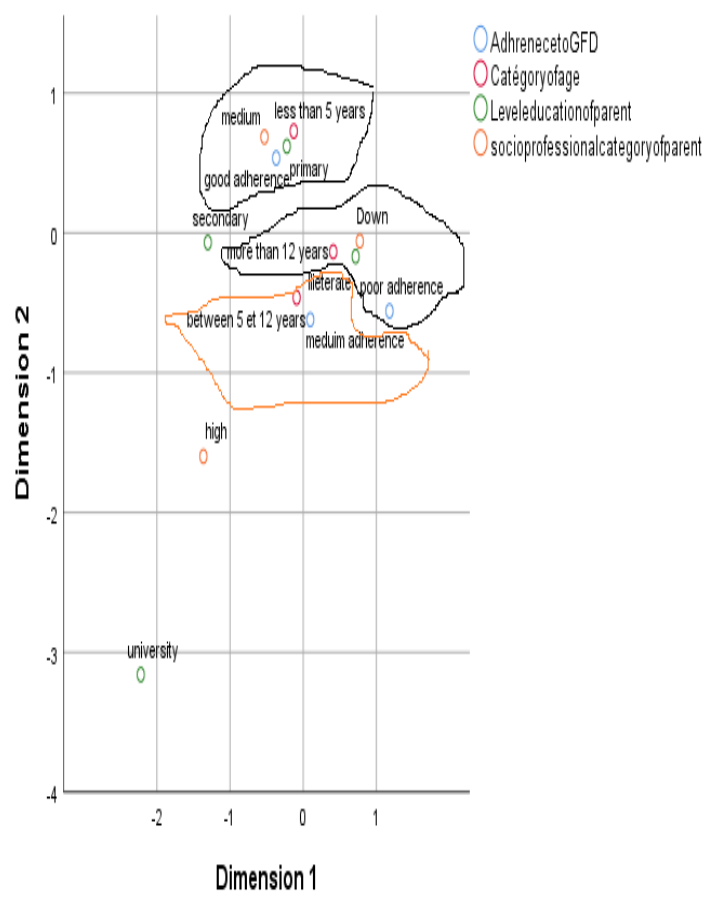

Fig. 2. ACM factor map of adherence to the glutenfree diet and socio-economic and demographic factors.

\section{Factors that influence the adherence to gluten-free diet}

The questionnaire is aimed at 127 parents or proxies of celiac children and adolescents. They were asked to confirm or not the contribution of these factors in the failure of GFD. $96 \%$ of the parents or proxies stated that media awareness is poor and in their opinion a factor in the failure to adhere to the GFD. The role of awarenessraising by the media (TV, radio, newspapers) is omniabsent. On the other hand, only $23 \%$ who see social networks as a factor of failure. The majority of parents or proxies saw that social networks (Facebook, what sup) play a primary role in adherence to the GFD. The creation of closed or open groups in these social networks allowed the exchange of ideas on CD and the GFD. However, these exchanges are only the experiences of patients in the absence of qualified personnel in this group such as pediatricians and dieticians. This can lead to the communication of false information which can distort the diet (Figure 3).

Cultural and psychological factors also contribute to the failure to adhere to the GFD with $81 \%$ and $61 \%$ respectively. The culture of Moroccans is based on the consumption of wheat-based foods. this diet implies a change in eating habits which causes a change in cultural life. This makes its application so difficult, especially for children who still live with a family under the same roof. The quality of life is so impacted. According to several studies, the quality of life among celiac children and adolescents is so poor [4], [15]-[18].

$78 \%$ of the respondents also see that cooking at home is a factor in the failure to provide adequate single-use equipment for celiac patients. Cross-contamination at home is common during the preparation of gluten-free meals. Firstly, the blenders used to grind cereals or other foods by celiac patients are very expensive. This makes cross-contamination common if the washing is not done properly. So, it is advisable to rigorously apply methods for cleaning kitchen equipment and utensils[19].

Consultation with pediatricians and dieticians is not a major factor in failure. Almost half of the patients regularly visit them at home. These consultations improve the level of knowledge about gluten. Half of the parents or proxies see this last factor (knowledge about gluten) as a factor in failure.

Finally, in-food service meals are not a factor of failure. Only $39 \%$ see the opposite. This is mainly due to the fact that parents prevent their children from eating away from home.

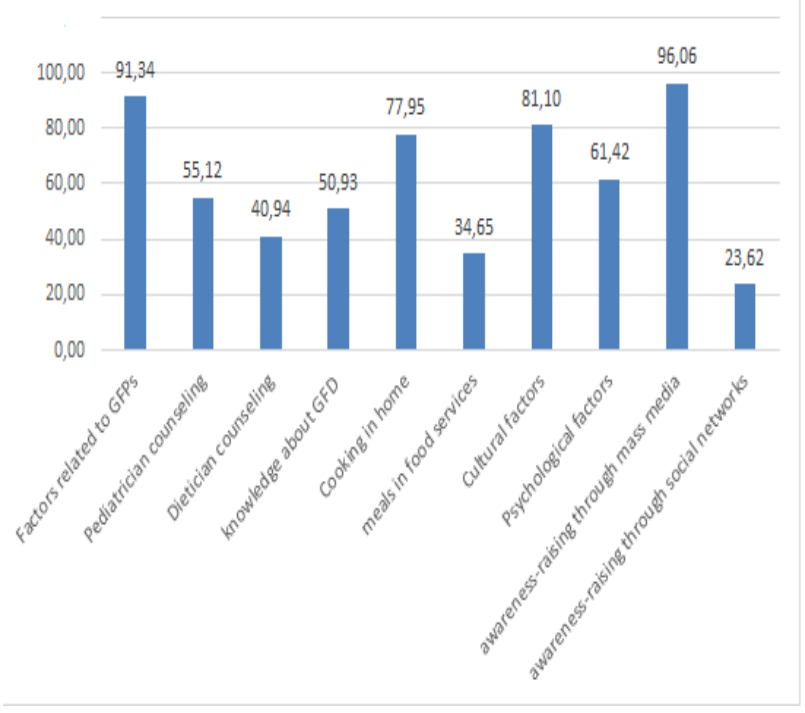

Fig.3. Factors affecting the adherence to gluten-free diet

Among 91\% of the respondents see GFPs as one of the major contributing factors to the failure of a GFD. The problems associated with GFPs are diverse, mainly citing their price, availability, labelling and nutritional quality. $72 \%$ of parents and proxies see that GFPs are not available in supermarkets (Figure 4). Their price is so exorbitant according to $80 \%$ of the answers. Even though the production of gluten-free foods by manufacturers has increased considerably over time, the price of GFPs is still very high [20], their availability is still limited with an exorbitant price [21] [22] [23]. Nutritional quality is poor according to $72 \%$ of responses. It is remarkable that these 
gluten-free foods are not enriched with nutrients such as iron and folic acid. These elements are necessary to reward the deficits noticed in celiac patients due to malabsorption secondary to the destruction of intestinal villi. This is confirmed by a study carried out in Morocco in 2020 which showed that the nutritional quality of PFG is unbalanced [24]. This impacts on the quality of life of Moroccan patients, which is poor in Moroccan children[25].

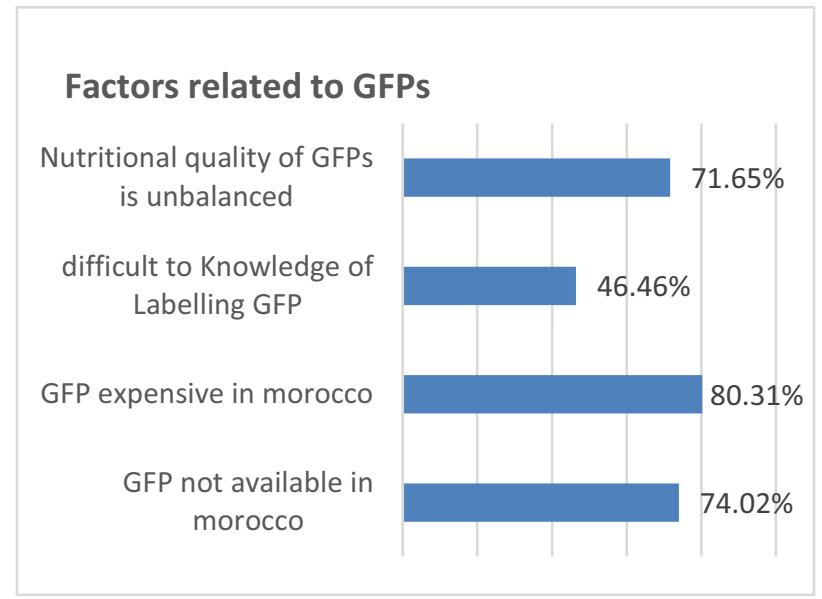

Fig.4. Factors related to gluten-free foods

The association between GFF-related factors and socioeconomic and demographic factors has shown that GFPs are more available in the urban environment. These people have a high economic situation considering that GFPs are cheap. While the availability of GFPs is mostly correlated with a very expensive price, especially in rural areas where the educational level of parents is dominated by illiterate parents, the availability of GFPs is also very high in rural areas (Figure 5).

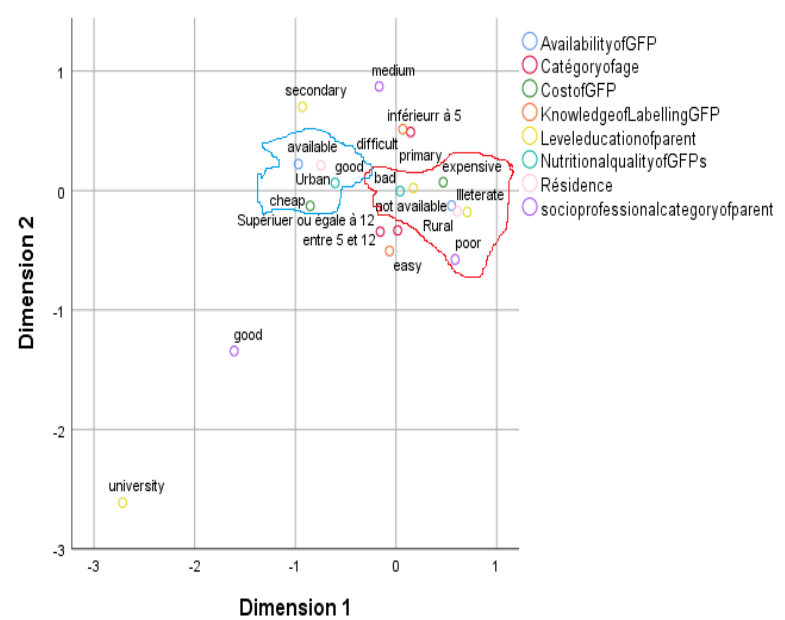

Fig.5. ACM factor map of factors related to gluten-free products and socio-economic and demographic factors.

\section{Conclusion}

Half of Moroccan celiac children and adolescents have a good adherence to the GFD. However, 13\% have poor adherence. Adherence is poorer among children and adolescents in rural areas than in urban areas. Poor adherence is also correlated with parents with low economic and educational levels. The factors are diverse, mainly citing the lack of awareness via the mass media (TV, radio, newspapers), cross-contamination during cooking at home, psychological factors and cultural factors. Factors related to GFPs contribute greatly to the failure of GFD. GFPs are scarcely available, expensive, and of poor nutritional quality. This situation is more serious in rural areas and among parents with low economic and educational levels.

\section{List of Abbreviation:}

CD: Celiac disease

GFD: Gluten-free diet

GFPs: Gluten-free products

\section{References}

1. B. Admou, M. Sbihi, F. Bienvenu, et L. Chabaa, Diagnostic immunologique de la maladie coliaque chez l'enfant. Mise au point, ImmunoAnal. Biol. Spéc, 24 (4), 217-222, août 2009, doi: 10.1016/j.immbio.2009.06.005.

2. G. Malamut et C. Cellier, Maladie coeliaque, Rev. Médecine Interne, 31(6), 428-433, juin 2010, doi: 10.1016/j.revmed.2009.04.009.

3. P. Singh et al., Global Prevalence of Celiac Disease: Systematic Review and Meta-analysis, Clin. Gastroenterol. Hepatol, 16(6), 823-836.e2, juin 2018, doi: 10.1016/j.cgh.2017.06.037.

4. M. Guennouni, N. Elkhoudri, A. Bourrhouat, et A. Hilali, Assessment of quality of life in children, adolescents, and adults with celiac disease through specific questionnaires: Review S0985056220304684, Clin. mai 2020, doi: 10.1016/j.nupar.2020.03.006.

5. F. Penagini, D. Dilillo, F. Meneghin, C. Mameli, V. Fabiano, et G. Zuccotti, Gluten-Free Diet in Children: An Approach to a Nutritionally Adequate and Balanced Diet, Nutrients, 5(11), p. 4553-4565, nov. 2013, doi: $10.3390 /$ nu5114553.

6. A. Løvik, G. Skodje, J. Bratlie, M. Brottveit, et K. E. A. Lundin, Diet adherence and gluten exposure in coeliac disease and self-reported non-coeliac gluten sensitivity, Clin. Nutr., 36 (1), 
275-280, févr. 2017, doi: 10.1016/j.clnu.2015.11.017.

7. E. Sevinc, La Influencia De Los Heterodímeros Hla-Dq2 En Las Características, Nutr. Hosp,6, 2594-2599, déc. 2015, doi: 10.3305/nh.2015.32.6.9733.

8. A. Lanzini et al., Complete recovery of intestinal mucosa occurs very rarely in adult coeliac patients despite adherence to gluten-free diet, Aliment. Pharmacol. Ther., 29(12), 1299-1308, juin 2009, doi: 10.1111/j.13652036.2009.03992.x.

9. K. MacCulloch, Factors affecting adherence to a gluten-free diet in children with celiac disease, 19 (6), 2014.

10. V. Xhakollari, M. Canavari, et M. Osman, Factors affecting consumers' adherence to gluten-free diet, a systematic review, Trends Food Sci. Technol., 85,23-33, mars 2019, doi: 10.1016/j.tifs.2018.12.005.

11. L. Elli et al., Diagnosis of gluten related disorders: Celiac disease, wheat allergy and non-celiac gluten sensitivity, World J. Gastroenterol., 21(23), 7110-7119, juin 2015, doi: 10.3748/wjg.v21.i23.7110.

12. K. El Fakiri, A. Bourahouate, A. Hadi, I. A. Sab, et M. Sbihi, La maladie coliaque du nourrisson et de l'enfant au CHU de Marrakech, J. Pédiatrie Puériculture, 29(6), 289-294, déc. 2016, doi: 10.1016/j.jpp.2016.08.004.

13. F. Boukezoula et M.-N.-E. Zidoune, Observance $d u$ régime sans gluten et ses conséquences sur l'état nutritionnel et la santé chez 100 malades coeliaques à Tébessa, Algérie, Médecine Mal. Métaboliques, 8(4), 440-444, sept. 2014, doi: 10.1016/S1957-2557(14)70850-8.

14. P. Rajpoot, A. Sharma, S. Harikrishnan, B. J. Baruah, V. Ahuja, et G. K. Makharia, Adherence to gluten-free diet and barriers to adherence in patients with celiac disease, Indian J. Gastroenterol., 34(5), 380-386, sept. 2015, doi: 10.1007/s12664-015-0607-y.

15. M. Pico, M. F. Spirito, et M. Roizen, Calidad de vida en niños y adolescentes con enfermedad celíaca: Versión argentina del cuestionario especifico $C D D U X$, p. 9.

16. R. K. van Doorn, L. M. Winkler, K. H. Zwinderman, M. L. Mearin, et H. M. Koopman, CDDUX: A Disease-specific Health-related Quality-of-life Questionnaire for Children With Celiac Disease, J. Pediatr. Gastroenterol. Nutr., 47(2), 147-152, août 2008, doi: 10.1097/MPG.0b013e31815ef87d.

17. D. M. Pico et M. F. Spirito, ADAPTACION TRANSCULTURAL DEL CDDUX: Versión Español-Argentina de un cuestionario de calidad de vida relacionado a la salud específico para niños con enfermedad celíaca, p. 7.
18. M. T. C. Lins, R. M. Tassitano, K. G. Brandt, M. M. de C. Antunes, et G. A. P. da Silva, « Translation, cultural adaptation, and validation of the celiac disease DUX (CDDUX), J. Pediatr. (Rio J.), 91(5), 448-454, sept. 2015, doi: 10.1016/j.jped.2014.11.005.

19. V. M. Weisbrod, J. A. Silvester, C. Raber, J. McMahon, S. S. Coburn, et B. Kerzner, Preparation of Gluten-Free Foods Alongside Gluten-Containing Food May Not Always Be as Risky for Celiac Patients as Diet Guides Suggest , Gastroenterology, 158(1), 273-275, janv. 2020, doi: 10.1053/j.gastro.2019.09.007.

20. P. Cureton et A. Fasano, The Increasing Incidence of Celiac Disease and the Range of Gluten-Free Products in the Marketplace, in Gluten-Free Food Science and Technology, E. Gallagher, Éd. Oxford, UK: Wiley-Blackwell, 2009, p. 1-15. doi: 10.1002/9781444316209.ch1.

21. A. R. Lee, B. Lebwohl, E. Ciaccio, R. Wolf, E. Ellis, et P. H. R. Green, Persistent Economic Burden of the Gluten Free Diet, Gastroenterology, 152(5), S265-S266, avr. 2017, doi: 10.1016/S0016-5085(17)31188-5.

22. J. Singh et K. Whelan, Limited availability and higher cost of gluten-free foods: Availability and cost of gluten-free foods, J. Hum. Nutr. Diet., 24 (5), 479-486, oct. 2011 , doi: 10.1111/j.1365277X.2011.01160.x.

23. M. Guennouni, N. El Khoudri, A. Bourrouhouate, et A. Hilali, Availability and cost of gluten-free products in Moroccan supermarkets and e-commerce platforms, $\mathrm{Br}$. Food J., déc. 2020, doi: 10.1108/BFJ-06-20190411.

24. M. Guennouni, N. El Khoudri, A. Bourrhouat, et A. Hilali, « Nutritional quality of gluten-free products in Moroccan supermarkets and ecommerce platforms ", Cereal Chem., 97(5), 912-920, sept. 2020, doi: 10.1002/cche.10313.

25. M. Guennouni, B. Admou, N. El Khoudri, A. Bourrhouat, A. Fguirouche, N. Jean Claude, et A. Hilali. Quality of life in Moroccans coeliac children and adolescent: Arabic translation and validation of a coeliac disease DUX. Journal of pediatric nursing. (2021). Doi: 10.1016/j.pedn.2021.06.011. 